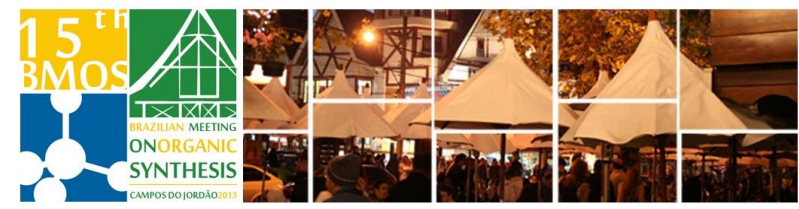

\title{
An experimental and theoretical study of the cycloaddition reactions of carbomethoxy-para-benzoquinones with 6,6-dimethyl-fulvene
}

\author{
Bruno M. Servilha, Maria C. Donatoni, Kleber T. de Oliveira, Marco A. B. Ferreira and \\ Timothy J. Brocksom*
}

\begin{abstract}
Departamento de Química, Universidade Federal de São Carlos, São Carlos-SP, 13565-905, Brazil.
\end{abstract}
${ }^{*}$ Corresponding author: e-mail: brocksom@terra.com.br. www.lqbo.ufscar.br.

Keywords: Diels-Alder reaction, 6,6-dimethyl-fulvene, para-benzoquinones, DFT calculations

\section{INTRODUCTION}

The Diels-Alder reactions of non-symmetric parabenzoquinones with simple dienes can furnish promising intermediates for the synthesis of bioactive natural products ${ }^{1}$. We now present our results on the Diels-Alder reactions of 6,6-dimethylfulvene and carbomethoxy-substituted parabenzoquinones. DFT calculations were also performed for the reactions reported herein.

\section{RESULTS AND DISCUSSION}

Our study began with the reactions between the carbomethoxy-para-benzoquinones (1 and 2) and 6,6-dimethyl-fulvene (3), in DCM at room temperature, for 24 hours (Table 1). Surprisingly, we have observed, for both reactions, the formation of single cycloadducts, which arise from the hetero Diels-Alder reaction of the para-benzoquinone tautomers (1' and 2') with 3. We do not observe the formation of cycloadducts 4 and 5 , which could have been formed by the direct Diels-Alder reaction (Scheme 1).

Scheme 1. Cycloaddition reactions of 6,6-dimethyl-fulvene (3) with carbomethoxy-para-benzoquinones ( 1 and 2 ).
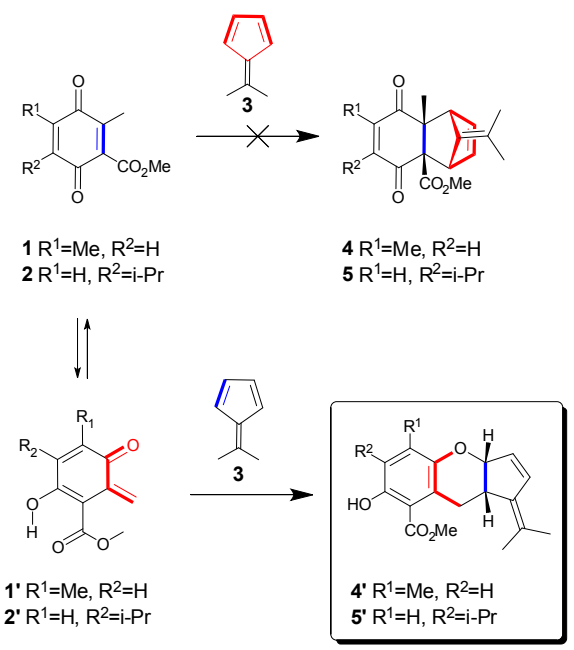

Table 1. Diels-Alder reactions of dienophiles 1' and 2' with 3

\begin{tabular}{|c|c|c|c|}
\hline Entry & Dienophile & Product & Yield (\%) \\
\hline 1 & $\mathbf{1}^{\prime}$ & $\mathbf{4}^{\prime}$ & 80 \\
\hline 2 & $\mathbf{2}^{\prime}$ & $\mathbf{5}^{\prime}$ & 72 \\
\hline
\end{tabular}

Gas-phase DFT calculations at the M062x/cc-pvdz level of theory were employed in order to compare the energetics of both pathways shown above. The activation energies and relative stabilities of the cycloadducts were evaluated (Figure 1).

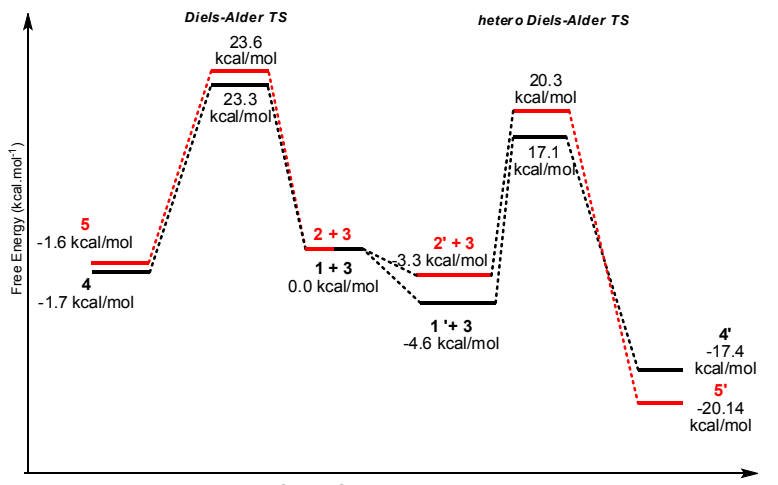

Figure 1. Reaction profiles for the cycloaddition reactions. Free energies in kcal.mol ${ }^{-1}$.

\section{CONCLUSION}

The observed experimental outcome for these reactions is in good agreement with our theoretical calculations, as the hetero Diels-Alder pathway involving the para-benzoquinone tautomers (1' and 2', with internal hydrogen bonding) shows lower activation energy barriers, and the more stable cycloadducts.

\section{ACKNOWLEDGEMENTS}

To FAPESP (2011/13993-2, 2013/02311-3 and 2013/06532-4), CAPES and CNPq.

\section{REFERENCES}

${ }^{1}$ Brocksom, T. J.; et. al. "Diels-Alder Reactions in the Synthesis of Higher Terpenes," in Organic Synthesis: Theory and Applications, T. Hudlicky (ed). JAl/Elsevier, Vol. 5, 39-87, 2001. 